\title{
COURSE OF "COMPUTER GEOMETRY" IN THE EDUCATIONAL PROCESS OF THE UNIVERSITY
}

\author{
Akan Mubarakov, ${ }^{1}$ Jaroslav Kultan, ${ }^{2}$ Ainash Davletova, ${ }^{3}$ Mira Rakhimzhanova ${ }^{4}$
}

\begin{abstract}
When considering the various areas of computer mathematics, especially geometry sticks out, where the problem analysis clearly and fully illustrates the computer. The discipline called "Computer Geometry" (F.Preparato, M.Sheymos) worthily appreciated by modern scientists. However, the practice of training in the higher education institutions (especially training of future teachers), does not provide studying of the Computer Geometry as an academic subject. Perspectives and methodology of Computer Geometry are developed by detailed study of specific problems, and the selection of the content of such course should be conducted on the basis of certain principles, all of which in total have to reflect the prospects of formation of the identity of the trainee as the subject of education adequately.
\end{abstract}

UDC Classification: 378; DOI: http://dx.doi.org/10.12955/cbup.v5.1016

Keywords: education, computer mathematics, computer geometry, specialty, content, informatics, training, principles.

\section{Introduction}

Education Reform in the current socio-economic conditions has specific requirements for teacher training. Modern teacher of Mathematics and Computer Science is required to possess not only the mathematical material and traditional teaching methods but also new, including information technology training. New forms and methods of training of highly qualified specialists who are able to use the computer in teaching of various disciplines competently are under active search in recent years.

One of the most effective means of developing the competencies of future teachers is the introduction into the educational process of various special courses. However, literature analysis shows that at pedagogical high schools the system of special courses on Mathematics and, in particular on Geometry by using computers has not developed yet.

The content of education in pedagogical institutions is intended to ensure a high mathematical and professional training of teachers. The main content of education is supplemented by various special courses.

\section{Research analysis}

Algorithmic study of these and other problems had appeared in the scientific literature in the last century, and their intensity has increased in the past two decades. However, a systematic study of geometric algorithms has been made only recently and this discipline, named by F. Preparato and M. Sheymos "Computer Geometry " worthily appreciated by modern scientists. (Pervin, 1992)

Perspectives and methodology of Computer Geometry are developed by the detailed study of specific problems. One of the main characteristics of this discipline is to realize that the classic characteristics of geometric objects often do not have an impact on designing of efficient algorithms. To overcome this drawback, it is necessary to find useful concepts and set their properties to facilitate the computer efficiency. In short, the computer geometry must convert the classic discipline into its computer form where it is necessary.

Methods of Computer Geometry are based on the works of great scientists (K. Gauss, I.Newton, A. Cauchy, Sh. Hermit, B.G. Galerkin, A.N. Krylov, N.I. Lobachevskii, P.L. Chebyshev, L. Eiler. and etc.), and also substantial contribution to the development of Computer Geometry was made by American scientists as F. Preparato and M. Sheymos, who managed to unite, broaden and deepen existing knowledge of this science. (Pervin, 1992).

\footnotetext{
${ }^{1}$ Ph.D., L.N.Gumilyov Eurasian National university, Faculty of information technologies, Informatics department, akanmubarak@mail.ru

${ }^{2}$ Ph.D., University of Economics in Bratislava, Faculty of Economic Informatics, Department of Applied Informatics, Jaroslav Kultan, jkultan@gmail.com

${ }^{3}$ Candidate of Pedagogic Sciences, PhD, L.N. Gumilyov Eurasian National university, Faculty of information technologies, Informatics department, ainash_5@mail.ru

${ }^{4} \mathrm{PhD}$ student, PhD, L.N.Gumilyov Eurasian National university, Faculty of information technologies, Informatics department,r.mira@mail.ru
} 


\section{Impact of research}

Computer Geometry is a young and rapidly developing field of applied mathematics. Its uprising was caused primarily by the invention and widespread introduction of personal computers into our lives, an essential element of which is a flat screen, which provides feedback to the user.

With the advent of personal computers, there was an opportunity to work with a flat electronic image by controlling it "directly" (in real time) by a sufficiently powerful computing device. In its turn, this led to significant changes in the areas of human knowledge, which anyway connected with geometry and visual (usually flat) representation of graphical objects - for example, in the drawing, design, construction, various modelling (both technical and art), medical diagnostics, design practice, and so on.

Currently, the using of personal computers in all these areas is not a surprise, although 30 years ago many of them worked without any computing devices. However, the last-user is not always aware of the fact that behind those programs that allow him to work with the screen image lays a rather complicated modern mathematics. In the first place, it is a differential geometry, and that is a differential geometry, which is the foundation and source of many important ideas for the modern Computer Geometry.

Many exhibitions are regularly held worldwide, for example, the SIGGRAPH, the pictures drawn by the computer. Development of fractals would be impossible without computers with the appropriate graphical display means. Multimedia has led to the emergence of new sources of information, which combine the static and video images, text, and sound. The latest operating systems work in graphical mode and initially implemented the methods of computer graphics.

Further, we consider the publications, the authors of which invest particular sense in the content of Computer Geometry.

The training aid of E.E. Sirotina (Nikulin, 2003) thoroughly investigates the mathematical foundations of computer graphics. Therewith, it is revealed the structure of such concepts as: the concept of homogeneous coordinates, geometric transformations on a plane, a parametric equation of the line in a plane, point-like normal equation of the straight line in a plane, the determinant equation of a line in a plane, the intersections of straight lines and line segments in a line, geometric transformations in threedimensional space, rotary movement toward an arbitrary vector, linear interpolation and twinning, the parametric equation of the line in three-dimensional space, the parametric equation of a plane in threedimensional space, the plane equation in point like normal form, determinant equation of the plane, the intersection of a line and a plane in three-dimensional space, and others.

Many books on Computer Graphics deeply explore narrowly specialized areas such as the development of subroutine libraries for the implementation of the method of backward ray or highspeed methods for displaying three-dimensional scenes that are used in computer games, or low-level programming of video adapters. Thus, for example, for students who are just beginning to investigate this area, often suffer from lack of general information, which allows to navigate in the rapidly expanding field of computer graphics.

The texts of lectures, authored by A. Kazantsev (Kuk and Beyz, 1990), are a tutorial for beginners to learn computer graphics that is the material aimed at compensating of above-mentioned gap. Also, there is information necessary for the development of three-dimensional applications of computer graphics. The textbook is based on a special course of lectures read by the author for four years at the Kazan State University, on the Faculty of Computational Mathematics and Cybernetics, while maintaining a close connection with the best traditions of classical Russian education.

The work of Kostnikov (2011), shows the role of geometric transformations in the systems of computer graphics. The regularities and features of application of shift transformations, rotation, scaling, reflection, and the central projection in two-dimensional and three-dimensional computer graphics are described there. The lecture notes are designed for students of specialist programmes, bachelor's and master's degrees in technical specialties.

"Training not only in mathematics but also by mathematics" is the leading idea of the academic and methodological complex on mathematics, aimed at strengthening the common cultural sounding of geometrical education and increasing its relevance to the formation of the personality of the future 
specialist.

The content of the material is aimed at developing students' ability to observe, to compare, to generalize, to find simple patterns, allowing them to learn different methods of reasoning, logic thinking, developing divergent thinking as an essential component of mental activity, geometric culture and allows you to expand ideas about the world by means of mathematics.

The aim of work "Computer Graphics" by Porev (2002) is to develop the aid of computer graphics for students who also study programming. The programming facilitates the perception of computer information technology, it allows insight into the world of computers, to get answers to many questions such as "why so."

The main feature of the course is that it is useful to construct a computer graphics course from the viewpoint of programmers. For a better perception of the course, it is desirable at least to be able to program on computer language $\mathrm{C}++$ or $\mathrm{C}$. The material represented in this book considerably corresponds to a course of computer graphics that was read by the author at the Kiev Technical Institute for the last several years. The experience of the author as one of developers and programmers of a geographic information system "OKO" was useful for writing the book. This manual is an attempt of the author to generalize some aspects of the current state of computer graphics, to write about them using simple and clear language as much as possible, accurately and clearly explain an essence of things. It is primarily for those who want to create something of his own and get satisfaction from the creative process. Computer graphics gives you endless scope for creativity, it excites the human imagination which is one of the factors of its popularity.

Work of Sosnin (2008) is a part of the electronic educational complex on discipline "Computer Graphics," including the curriculum, laboratory practice, guidelines for coursework, methodical guidelines on practical training, methodical guidelines for self-work, testing and assessment materials "Computer graphics. Bank of tests", visual aid "Computer graphics. Presentation materials". The mathematical foundations of computer graphics are considering there. Geometric transformations of points, straight lines, two-dimensional and three-dimensional transformations of projections are given. The computational models of solving geometric problems are also presented. Designed for students of the following specialties: "Vocational training (on branches)," "Education and Pedagogy," "Automated Information Processing and Management," "Software of computer facilities and the automated systems," "Computer Science and Engineering." The content of school subjects EUMK focused on promoting and supporting the emotional and intellectual development of students; to create conditions for the demonstration of self-dependence, initiativity, creative abilities of students.

Book named "Computer Graphics" Porev (2002) considers the types of computer graphics, software of computer graphics, geometric modeling. Basic concepts of geometric modeling, Affine transformation, geometric models of flat objects, methods (models) of describing a straight line, the mutual arrangement of graphic elements on a plane, equations of the beam of lines and the bisector of the angle, curves of the second order. Splines. Bezier curves and etc. The material presented in the textbook purposefully creates all kinds of learning activities of students. This is facilitated by: a logically built course content, a variety of methods of educational activity of students,educational tasks directed to carry out different types of actions by students.During the course students acquire: mathematical knowledge, abilities, and skills, and they will learn how to use them to describe the regularities, processes, phenomena, assessment of quantitative and spatial relations; will seize abilities: to build reasonings; to reason and adjust statements to differentiate reasonable and unreasonable judgments; to reveal regularities; to establish causes and effect relationships; to perform the analysis of various mathematical objects, allocating their essential and insignificant signs that will provide them successful continuation of mathematical education.

The main features of the content of the course "Computer geometry and graphics" (Golubenko, 2009) are: integrative presentation of knowledge; targeted skills development during the mastering subject knowledge and skills. The paper deals with a wide range of issues in the field of computer graphics: the basic concepts are defined, a row of classical algorithms is considered, the review of the modern hardware and software facilities of computer graphics is given. 


\section{Continuity of study}

Broad integration of knowledge in which connections of a different level (metadisciplinary, intersubject and intrasubject) allow to reach the main objective - to show students a wide aggregate picture by means of science, and direct learning. The course organically combines work on perception of classical algorithms, the modern hardware and software facilities of computer graphics.Also designed for the students of technical specialties.

Nikulin (2003) gives the most complete presentation of geometric and algorithmic fundamentals of modern computer graphics: mathematical models of graphic elements on a plane and in space, the fundamental laws of geometric optics and the algorithms based on them for the construction of optical effects, the methods of geometric transformation, analysis and synthesis of models of lines, surfaces and volumes, geometric visualization tasks - a complex of algorithms for $2 \mathrm{~d}$ - and 3d-clippings, block diagrams of algorithms and examples of their implementation. It is useful for the students of the higher education institutions and specialists studying computer graphics and who are engaged in the development of new algorithms and applied graphical programs.

N.N.Glagolev's study guide deals with mathematically rigorous stated all the relevant information from differential geometry and topology, the basic concepts and tools of computer geometry, the mathematical description of some important algorithms of geometrical modeling and automatic designing are given there. The latest results of achievements in the field of computer processing of modern digital image - the splice of projectively converted images are also described. It is written for students of higher educational institutions of technical direction. The author proceeds from the fact that the foundations of geometric modeling are differential geometry and topology, and the working materials are different curves and surfaces. At the same time, geometric modeling also develops its own methods.

The common feature of all system of textbooks is that the same educational content may be in the form of visual and / or verbal (or other) images in the form of theory, as a collection of facts and other. A variety of presentation of educational content allows you to activate different types of thinking visual-active, eye-mindedness, verbal and figurative, verbal and logical (theoretical); different types of perception and processing of information like kinesthetic and visual, and as a whole creates prerequisites for the individualization of training and retention of learning. One and the same object (phenomenon) is treated with the great possible number of parties. Knowing about it is naturally fixed in the student's mind as with the other study material and a personal experience. Knowledge becomes valuable, gains the personal importance and practical sense. It gives a chance to each student to show the strengths and to develop insufficiently created skills.

As Kuk and Beyz (1990) consider the computing an exact science, and the systematic examination of all aspects, including such areas as database development, system testing and the development of software with the need to use mathematical models. From this perspective, many training programs in computing at universities and institutes provide special courses that acquaint students with the relevant mathematical structures and methods.

Teacher training program doesn't provide studying of computer geometry as an academic subject, though it is a very interesting area of geometry, therefore, it would be reasonable to introduce it in a variable part of the training program.

\section{Conclusion}

Summing up the result we can say that the selection of educational material, its restructuring should be conducted on the basis of certain principles (criteria), which together should adequately reflect the prospects of forming of the identity of the trainee as the subject of education, social actions and educational and productive activities on the basis of pedagogical forecasting data. From this point of view, we can offer the following principles in the training content forming:

- correspondence of training content to the requirements of modern production and socio-economic forecasting of the region;

- the accounting of the substantial and procedural parties of training (when developing the content of a training material it is necessary to take into account the regularities, methods, the principles of training; it is necessary to reflect in programs and textbooks the ways of conveying and learning, also 
learning levels along with the content);

- a unified approach to designing of the content of education (theoretical aspect, subject, training material, pedagogical activity, the identity of the students).

\section{References}

Golovanov NN Ilyutko DP And others. (2006) Computer geometry: Proc. allowance for students. universities / - Moscow: Publishing Center "Academy",. - 512 p. - (University textbook Ser Applied Mathematics and Informatics..).

Golubenko E.V. (2009) Computer geometry and graphics. -Rising On Don. - 200c.

Kazantsev A.V. (2001) Basics of computer graphics. The texts of the special lectures. Part 1: The mathematics of computer graphics. -Kazan

Kosnikov Y.N. (2011), Geometric transformations in computer graphics. Summary lektsiy.- Penza

Kuk D, Beyz G. (1990), Computer mathematics. M .: Nauka. Ch. Ed. Sci. lit., 384 p.

Nikulin E.A. (2003) Computer geometry and computer graphics algorithms. -St. Petersburg. -560s.

Pervin N.N.(1992) Computer graphics on the computer science lessons: Vol. for teachers. M .: Prosveschenie

Porev V.,(2002) Computer Graphics. - SPb .: BHV-Petersburg, - 432 p: il.

Sirotin E.E.(2005) Computer geometry and graphics. Siberian Federal University. Department of artificial intelligence systems. Tutorial.

Snizhko E.A. (2005) Computer geometry and graphics. Baltic State Technical University. Printing BSTU. -

Sosnin N.V., (2008) Computer Graphics. Mathematical Foundations. Version 1.0 [electronic resource]: the electron. Proc. Benefit / NV Sosnin. -Electron. Dan. (4 MB). -Krasnoyarsk: IPK SFU. 